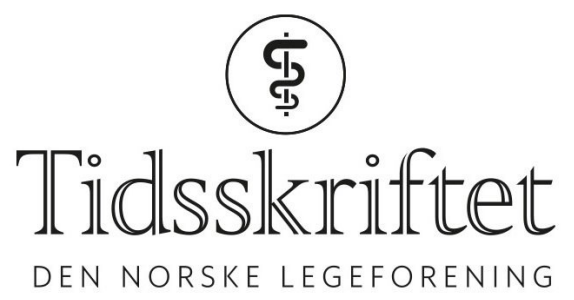

\title{
Skakvåld mot spädbarn - läkarens roll måste särskiljas från rättsväsendets roll
}

DEBATT

\section{NIELS LYNØE}

E-post: niels.lynoe@ki.se

Niels Lynøe är seniorprofessor i medicinsk etik vid Karolinska institutet i Stockholm och har speciellt forskat innom området empirisk etik.

Författaren har fyllt i ICMJE-formuläret och uppger inga intressekonflikter.

\section{ANDERS ERIKSSON}

Anders Eriksson är seniorprofessor i rättsmedicin vid Umeå universitet och har särskilt forskat om skador och skadeprevention.

Författaren har fyllt i ICMJE-formuläret och uppger att han som vetenskaplig rådgivare hos Socialstyrelsen sedan år 2003 de senaste tre åren har skrivit två expertutlåtanden i rättsliga förfaranden i samband med misstänkt barnmisshandel.

Både författarna utgjorde tillsammans med fyra kollegor den expertgrupp som genomförde den systematiska litteraturgranskningen av «shaken baby syndrome».

Det är bekymrande att forskare bortser från de allvarliga metodologiska bristerna i den befintliga vetenskapliga litteraturen om skakvåld. Cirkelargumentation hör inte hemma i vetenskapliga studier, och läkare ska avhålla sig från att bedöma uppsåt, som är en strikt juridisk fråga.

Vi instämmer med Arne Stray-Pedersen och hans 17(!) medförfattare när de i en kommentar (1) till Knut Westers artikel om skakvåld mot spädbarn (2) påpekar att det kan få fatala konsekvenser att missa att ett barn har utsatts för våld. För barnets bästa är det självfallet viktigt att barnmisshandel upptäcks, och att barnet skyddas från en farlig och riskfylld miljö. Men det ligger också i barnets intresse att inte i onödan omplaceras, att dess familj inte splittras på felaktiga grunder, och att en oskyldig förälder inte döms till fängelse. Detta är dilemmat mellan risken för underdiagnostik och risken för överdiagnostik som gör att diagnostiken av barnmisshandel måste vara så korrekt som möjligt. Och det var detta dilemma som var utgångspunkten för den svenska utredningen av den diagnostiska träffsäkerheten av triaden (subduralblödning, retinala blödningar och encefalopati) för att fastställa om ett spädbarn har skakats våldsamt (3). Denna frågeställning valdes eftersom det i vetenskapliga studier, i kliniska handlingsprogram och i flera rättsfall påståtts att triadfynd med mycket hög grad av säkerhet kan säkerställa att barnet skakats våldsamt. Utredningen initierades och genomfördes av Statens beredning för medicinsk och social utvärdering, vars uppgift är att utvärdera evidensen av exempelvis diagnostiska metoders träffsäkerhet. 
Som Knut Wester anger, är huvudproblemet med nästan samtliga tidigare studier om skakvåld att de har hög risk för bias på grund av cirkelargumentation, vilket beror på att man använt barnskyddteams bedömningar både som diagnostiskt test och som referenstest. På detta sätt elimineras alla falskt positiva och falskt negativa fall och den diagnostiska träffsäkerheten blir uppenbart orimliga $100 \%(4,5)$.

Stray-Pedersen och medarbetare (1) underkänner dock den svenska rapporten med hänvisning till den kritik som framförts mot rapporten. Den svenska rapportens huvudslutsats var att det finns otillräcklig vetenskaplig evidens ("very low quality») för att fastställa att ett spädbarn har skakats våldsamt när endast triaden påvisats (3). Vi som deltog i den svenska utredningen, var medvetna om att resultatet skulle uppfattas som kontroversiellt. Eftersom rapporten underkände så gott som samtliga de studier som de senaste 30 åren har använts för att fastställa diagnosen skakvåld, var efterföljande kritik knappast förvånande. Stray-Pedersen och medarbetare pekar dock på några punkter som bör kommenteras.

\section{Är det vanligt att triaden förekommer isolerat?}

Den svenska rapporten fokuserade på triadfall där det inte fanns några yttre tecken på trauma, eftersom det är just sådana isolerade triadfall som är intressanta. De är intressanta dels därför att dessa fall helt saknar traditionella tecken på yttre våld, dels därför att man borde förvänta sig att om en vuxen person greppar ett spädbarn och skakar det våldsamt, så borde det kunna uppstå åtminstone blåmärken (underhudsblödningar).

Stray-Pedersen och medarbetare menar emellertid att fokus på triaden inte avspeglar verkligheten eftersom de flesta rapporterade fall med triadfynd även har yttre tecken på trauma mot huvudet. Det sistnämnda är korrekt, men isolerade triadfall utgör så mycket som cirka en tredjedel av samtliga fall (6). Och just i denna tredjedel kanske man återfinner en del av den överdiagnostik som påpekats i flera epidemiologiska studier (7-9)? Författarna menar också att det «bærer helt galt av sted når [triaden] anvendes som eneste premiss for diagnose». Javisst, detta påstående understryks med kraft av den svenska rapporten! Men i motsats till författarnas uppgift att triaden inte används på detta sätt, har triaden i många vetenskapliga studier, i kliniska guidelines, och i en lång rad rättsfall påståtts utgöra en säker grund för diagnostik av skakvåld.

\section{Är retinala blödningar specifika?}

Stray-Pedersen och medarbetare hävdar att såväl subduralblödning som retinala blödningar vid skakvåld har ett «typiskt» utseende, och hänvisar bland annat till Vinchon och medarbetare, som fann en specificitet på $97 \%$ och ett positivt prediktivt värde på $96 \%$ för de retinala blödningarna (10). Dessa värden är så höga att de omedelbart borde medföra skepsis mot hur man kommit fram till dem. Detta har Vinchon faktiskt också själv medgivit (11), men uttalade då också att det är sådana resultat som en domare vill ha! När Vinchon och medarbetare sedan beräknade specificitet och positivt prediktivt värde för triaden blev båda dessa mått helt orimliga 100 \%! Anledningen var att man hade ersatt den traditionella triadens encefalopati med «frånvaro av yttre tecken på trauma». Eftersom de flesta (alla?) barn som varit med om en trafikolycka - till skillnad från de misstänkt skakade barnen - har yttre tecken på trauma, eliminerades samtliga falskt positiva fall, och därmed blev både specificiteten och det positivt prediktiva värdet perfekt $(10,12)$.

Även av andra skäl är retinala blödningar knappast specifika för skakvåld. När ögonläkare som inte kände till omständigheterna i fallen (var «blindade») skulle avgöra om en RetCambild av retinala blödningar kom från ett misstänkt skakvåldsfall, ett sjukdomsfall eller ett olycksfall, var deras diagnostik endast obetydligt bättre än slumpen (13). Som Knut Wester påpekar, förefaller det mer troligt att de retinala blödningarna i många fall är sekundära till ökat intrakraniellt tryck $(2,14)$. 


\section{Vilken betydelse har förlossningsrelaterade subduralblödningar?}

Mekanismerna bakom de retinala och de subdurala blödningarna förtjänar att studeras närmare, och Knut Wester har lyft fram frågan om benign extern hydrocefalus som en möjlig alternativ förklaring (2). En annan aspekt är de förlossningsrelaterade subdurala och retinala blödningarna (15). Subduralblödningar förekommer vid cirka $40 \%$ av alla normala vaginala förlossningar (15). Dessa blödningar har samma utseende som vid misstänkt skakvåld, men antas inte ge några symptom och resorberas vanligen inom 1-3 månader efter förlossningen. Vid assisterade förlossningar ökar förekomsten av subduralblödning till 57 \%, medan de vid ett planerat kejsarsnitt är 1,7\% (15). Sannolikt ger dessa subduralblödningar inte heller senkomplikationer, något man dock inte vet med säkerhet (16). Men i sällsynta fall skulle en sådan blödning kunna utvecklas till en kronisk subduralblödning med risk för re-blödning som spontant eller efter ett mindre trauma kan bli symptomgivande (17). Med tanke på att en subduralblödning kan kvarstå i åtminstone tre månader, är det också relevant att påpeka att «abusive head trauma» oftast diagnostiseras vid två månaders ålder (18).

\section{Cirkelargumentation har ingen plats i vetenskapliga studier}

Vi är bekymrade över att forskare inom området väljer att bortse från de avgörande metodologiska bristerna i den befintliga vetenskapliga litteraturen om skakvåld. Cirkelargumentation har ingen plats i vetenskapliga studier, oavsett hur många läkare, forskare och organisationer som är beredda att acceptera denna typ av logiska fallgropar. Man bör forska mer om mekanismerna till uppkomsten av både subdurala och retinala blödningar - exempelvis genom att följa förekomsten och spontanförloppet av subduralblödning det första halvåret efter förlossningen. Det finns flera konkurrerande hypoteser där den som hittills dominerat endast är en - som dessutom är fylld av paradoxala fenomen och defensiva hjälphypoteser (19).

Vi instämmer med Knut Wester att det behövs nya grepp i fortsatt forskning om «abusive head trauma» - en beteckning som försåtligt innefattar påståenden om såväl uppkomstmekanism som uppsåt av symptom som man inte med säkerhet vet om de ens orsakats av våld. Vetenskapssamhället måste vara öppet för att testa nya hypoteser med metoder som helt undanröjer de deletära effekterna av cirkelargumentation, och bör med självklarhet avhålla sig från att bedöma uppsåt, som är en strikt juridisk fråga.

\section{LITTERATUR:}

1. Stray-Pedersen A, Møller C, De Lange C et al. Legers rolle ved mistanke om alvorlig barnemishandling. Tidsskr Nor Legeforen 2018; 138. doi: 10.4045/tidsskr.18.0922. [CrossRef]

2. Wester K. Har et «filleristet spedbarn» alltid vært filleristet? Tidsskr Nor Legeforen 2018; 138. doi: 10.4045/tidsskr.18.0583. [CrossRef]

3. Lynøe N, Elinder G, Hallberg B et al. Insufficient evidence for 'shaken baby syndrome' - a systematic review. Acta Paediatr 2017; 106:1021-7. [PubMed][CrossRef]

4. Lynøe N, Elinder G, Hallberg B et al. Is accepting circular reasoning in shaken baby studies bad science or misconduct? Acta Paediatr 2017; 106:1445-6. [PubMed][CrossRef]

5. Lynøe N, Eriksson A. A diagnostic test can prove anything if you use incorrect assumptions and circular reasoning. Acta Paediatr 2018; 107: 2051-3. [PubMed][CrossRef]

6. Lynøe N, Eriksson A. Is focusing on the triad really irrelevant and of no practical use? Acta Paediatr 2018; 107: 1675-6. [PubMed][CrossRef]

7. Riggs JE, Hobbs GR. Infant homicide and accidental death in the United States, 1940-2005: ethics and epidemiological classification. J Med Ethics 2011;37: 445-8. [PubMed][CrossRef] 
8. Andersson J, Thiblin I. National study shows that abusive head trauma mortality in Sweden was at least 10 times lower than in other Western countries. Acta Paediatr 2017;3. doi: 10.1111/apa.14138.

[PubMed][CrossRef]

9. Högberg U, Lampa E, Högberg G. Infant abuse diagnosis strongly associated with SBS/AHT criteria: incidence increase in Sweden due to overdiagnosis? European Journal of Public Health 2018; 28: 641-6.

10. Vinchon M, de Foort-Dhellemmes S, Desurmont M et al. Confessed abuse versus witnessed accidents in infants: comparison of clinical, radiological, and ophthalmological data in corroborated cases. Childs Nerv Syst 2010; 26: 637-45. [PubMed][CrossRef]

11. Vinchon M. Response to Lynøe: questions about isolated trauma shaking and confessions. Childs Nerv Syst 2017; 33:1423-4. [PubMed][CrossRef]

12. Lynøe N, Rosén M, Eriksson A. Questions about isolated traumatic shaking and confessions. Childs Nerv Syst 2017; 33: 731-2. [PubMed][CrossRef]

13. Mulvihill AO, Jones P, Tandon A et al. An inter-observer and intra-observer study of a classification of RetCam images of retinal haemorrhages in children. Br J Ophthalmol 2011; 95: 99-104. [PubMed][CrossRef]

14. Minns RA, Jones PA, Tandon A et al. Raised intracranial pressure and retinal haemorrhages in childhood encephalopathies. Dev Med Child Neurol 2017; 59: 597-604. [PubMed][CrossRef]

15. Lynøe N, Eriksson A. May the fear of being falsely accused of having shaken a baby increase parents' demands for scheduled Caesareans? Acta Paediatr 2017; 106:1052. [PubMed][CrossRef]

16. Lynøe N, Olsson D, Eriksson A. Is delayed speech development a long term sequel to birth-related subdural hematoma? Am J Neuroradiol 2019; doi: 10.3174/ajnr.A589o. [PubMed][CrossRef]

17. Hymel KP, Jenny C, Block RW. Intracranial hemorrhage and rebleeding in suspected victims of abusive head trauma: addressing the forensic controversies. Child Maltreat 2002; 7:329-48.

[PubMed][CrossRef]

18. Parks S, Sugerman D, Xu L et al. Characteristics of non-fatal abusive head trauma among children in the USA, 2003-2008: application of the CDC operational case definition to national hospital inpatient data. Inj Prev 2012; 18:392-8. [PubMed][CrossRef]

19. Lynøe N, Juth N, Eriksson A. From child protection to paradigm protection - the genesis, development and defence of a scientific paradigm. J Med Philos 2018. [PubMed][CrossRef]

Publisert: 7. februar 2019. Tidsskr Nor Legeforen. DOI: 10.4045/tidsskr.19.0035

Mottatt 10.1.2019, første revisjon innsendt 24.1.2019, godkjent 24.1.2019.

(C) Tidsskrift for Den norske legeforening 2020. Lastet ned fra tidsskriftet.no 